ORIGINAL RESEARCH

\title{
Postexercise Peripheral Oxygen Saturation After Completion of the 6-Minute Walk Test Predicts Successfully Reaching the Summit of Aconcagua
}

\author{
Matthew P. Lazio, MD; Jon D. Van Roo, MD; Carlos Pesce, MD; Sanjeev Malik, MD; D. Mark Courtney, MD \\ From the Department of Emergency Medicine, Feinberg School of Medicine, Northwestern University, Chicago, IL (Drs. Lazio, Van Roo, \\ Malik, and Courtney); Madison Emergency Physicians, Department of Emergency Medicine, St. Mary's Hospital, Madison, WI (Drs. Lazio \\ and Van Roo); Departamento de Medicina Deportiva y Evaluación del Rendimiento Físico, Universidad Maimonides, Ciudad Autónoma de \\ Buenos Aires, Argentina (Dr. Pesce)
}

\begin{abstract}
Objective.-The 6-minute walk test (6MWT) is a single measurement of functional status in patients with cardiovascular disease. It has not been studied at high altitude. We investigate the screening value of 6-minute walk distance (6MWD) and postexercise vital sign (VS) measurements as predictors of successfully reaching the summit or development of acute mountain sickness (AMS) on Aconcagua (6962 m).

Methods.-Prospective observational cohort in Aconcagua Provincial Park, Argentina. Adults climbing the normal route who registered with base camp physicians were included. There were no exclusion criteria. VSs were measured before (resting) and after (postexercise) completion of 6MWT while volunteers acclimatized at Plaza de Mulas base camp (4365 m). Volunteers proceeded towards the summit at their own pace and upon descent returned a questionnaire with maximum altitude reached and Lake Louise AMS Self-report Score (LLSelf).

Results.-One hundred twenty-four volunteers completed the 6MWT. Sixty-four volunteers (51.6\%) completed questionnaires; $56 \%$ summited. Median LLSelf was 4 (IQR: 3.0-6.5). There was no association between any resting or postexercise VS measurements and AMS. However, mean postexercise $\mathrm{SpO}_{2}$ was $80.8 \%$ in summiters and $76.4 \%$ in nonsummiters, a difference of $-4.4 \%(95 \% \mathrm{CI}$ : -6.7 to $-2.0, p=0.0005)$. Postexercise $\mathrm{SpO}_{2}<75 \%$ had $97.2 \%$ sensitivity and negative likelihood ratio of 0.086 in predicting the outcome of successfully reaching the summit: only one climber with $\mathrm{SpO}_{2}<75 \%$ successfully reached the summit.

Conclusions.-This study provides the first published data on 6MWD recorded in the field at high altitude. Postexercise $\mathrm{SpO}_{2}<75 \%$ may be a useful screening test for predicting the outcome of successfully reaching the summit of Aconcagua.
\end{abstract}

Key words: hypoxia, altitude sickness, mountaineering, sensitivity and specificity, Aconcagua, 6-minute walk test

\section{Introduction}

High altitude is defined as an elevation greater than $1500 \mathrm{~m}$ above sea level, while extreme altitude is an elevation greater than $5500 \mathrm{~m}$ above sea level. ${ }^{1}$ Millions of people worldwide live or travel to high altitudes, and

Presented at Wilderness Medical Society Medical Conference and Annual Meeting, Snowmass, CO, July 2009 and at Illinois College of Emergency Physicians Academic Forum, First Place, Resident Research Competition, Chicago, IL, October 2009.

Corresponding author: Matthew P. Lazio, MD, 700 S. Park St, Room A404, Madison, WI 53715 (e-mail: matt.lazio@gmail.com). at least 20000 people trek to extreme altitude annually. As a result of decreased barometric pressure and decreased partial pressure of oxygen at altitude, individuals living in or visiting high altitude are at risk of developing adverse conditions secondary to hypoxia. The spectrum of high altitude illness (HAI) ranges from high altitude headache and acute mountain sickness to life-threatening conditions such as high altitude cerebral edema and high altitude pulmonary edema.

Predicting who may succumb to high altitude illness is difficult. Physical fitness alone does not protect against the development of $\mathrm{HAI}^{2}$; indeed, the incidence of AMS 
at $3000 \mathrm{~m}$ in the young, healthy adult population that comprises the majority of mountaineers is generally cited as greater than $30 \%{ }^{3}$ Most studies of predictor factors of HAI have focused on ascent rate, ${ }^{4}$ altitude of residence, ${ }^{5}$ preexposure, ${ }^{4}$ dynamic measurements after rapid ascent,${ }^{6}$ or static measurements performed at high altitude, such as pulse rate ${ }^{7}$ or oxygen saturation. ${ }^{8}$ Predicting who will successfully reach the summit of mountains at extreme altitude is even more difficult due to the numerous external factors that go into high altitude expeditions, including weather, fitness level, group dynamics, and development of HAI. Only recently have researchers begun to look at factors that contribute to successfully reaching a summit at extreme altitude. ${ }^{9-11}$ While optimal evaluation would assess the overall cardiopulmonary status in the field, there are few studies of dynamic functional measurements performed at high altitude.

Recently, base camp clinicians on the world's highest mountains such as Everest, ${ }^{12}$ Aconcagua, ${ }^{13}$ and Denali ${ }^{14}$ have begun to screen mountaineers for symptoms of AMS prior to their summit attempts in an effort to decrease mountaineering accidents. Ideal screening tests for HAI would be objective, inexpensive, lightweight, reproducible, and require no advanced equipment. The 6-minute walk test (6MWT) is one such test that utilizes distance walked in a defined period of time to objectively evaluate functional exercise capacity. The 6MWT was initially created to measure response to interventions in patients with moderate to severe cardiopulmonary disease, and has been extensively used outside of the high altitude setting. ${ }^{15}$ More recently, the 6MWT has been used as a single measurement of the functional status of patients across a broad spectrum of cardiovascular diseases, such as heart failure, ${ }^{16}$ chronic obstructive pulmonary disease,${ }^{17}$ pulmonary embolism, ${ }^{18}$ peripheral vascular disease, ${ }^{19}$ and cystic fibrosis. ${ }^{20}$ In that it requires only a hard, flat surface and the equipment required to record vital signs, the 6MWT may be well suited to evaluate the overall functional status of mountaineers in the high altitude setting.

At $6962 \mathrm{~m}(22841 \mathrm{ft})$, Aconcagua is the highest mountain in South America and the highest mountain outside of Asia. Greater than 6000 climbers visit Aconcagua Provincial Park annually, the vast majority of whom attempt to summit Aconcagua via the nontechnical Ruta Normal (Normal Route) on the northwest side of the mountain. We chose to utilize Plaza de Mulas base camp, situated at $4365 \mathrm{~m}$ (14 $321 \mathrm{ft})$, as our study setting. We performed the 6MWT in the field at high altitude $(4365 \mathrm{~m})$. Our primary objective was to determine if 6-minute walk distance (6MWD) or postexercise vital sign measurements correlated with successfully reaching

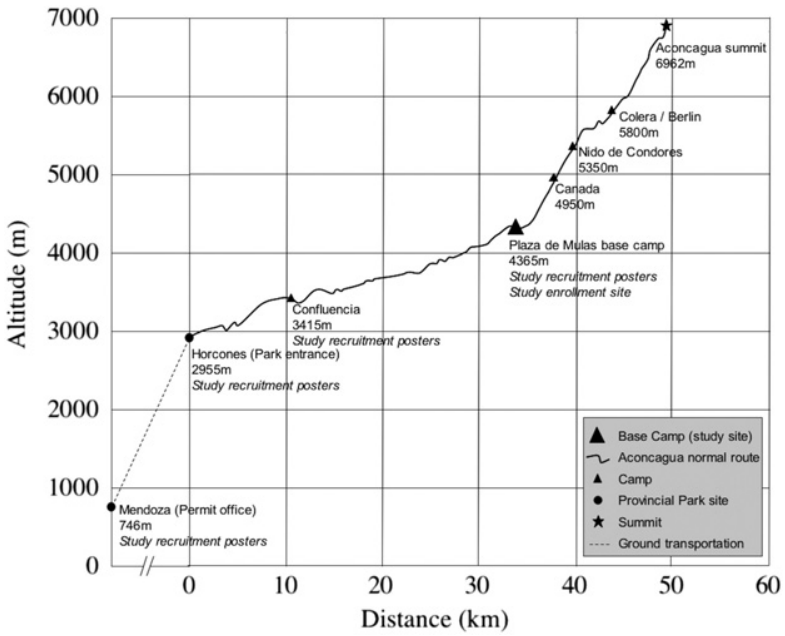

Figure 1. Altitude profile of the normal route of Aconcagua. Mountaineers must apply for a permit at the Department of Natural Resources office in the city of Mendoza $(746 \mathrm{~m})$. Trekkers who climb Aconcagua via the normal route enter the park at Horcones (2955 m), spend 1 to 2 nights at Confluencia $(3415 \mathrm{~m})$, and typically arrive at Plaza de Mulas base camp (4365 m) by day 3. From Plaza de Mulas, climbers proceed through the high camps of Canada (4950 m), Nido de Condores $(5350 \mathrm{~m})$, and Berlin or Colera $(5800 \mathrm{~m})$ on their way to the summit of Aconcagua (6962 m).

the summit of Aconcagua or subsequent development of AMS.

\section{Materials and Methods}

\section{STUDY DESIGN}

This study was performed on 9 nonconsecutive days between January 15 and 31, 2009 (3 days per week during the 2nd, 3rd, and 4th weeks of January 2009). It took place in Aconcagua Provincial Park, Mendoza, Argentina at Plaza de Mulas base camp (4365 m) on the Normal Route (Figure 1) to the summit of Aconcagua (6962 m [22 $841 \mathrm{ft}])$. Inclusion criteria were all climbers who had hiked by foot from Horcones to Plaza de Mulas (distance $33 \mathrm{~km}$, elevation gain $1410 \mathrm{~m}$ ), checked in with base camp physicians at Plaza de Mulas during the study period, were $>17$ years old, and spoke English, Spanish, French, or German. Park authorities require all climbers to check in with park rangers upon arrival at Plaza de Mulas and to check in with base camp physicians the day after arrival at Plaza de Mulas. For volunteers meeting the above criteria and willing to participate, there were no exclusion criteria. 6MWTs were performed at base camp. Volunteers then proceeded to the summit at their own pace. After they finished ascending, volunteers completed one questionnaire containing their self-reported maximum altitude reached and a Lake Louise AMS Self-Report Score (LLSelf), a previously validated 
instrument for measuring AMS. ${ }^{21}$ Volunteers were instructed to complete the LLSelf score that corresponded to the trekking day during which they subjectively felt worst. Upon descent to base camp, volunteers returned their questionnaires to the investigators.

\section{SIX-MINUTE WALK TEST}

Resting vital signs (peripheral oxygen saturation, heart rate, respiratory rate, and blood pressure) at base camp $(4365 \mathrm{~m})$ were measured after volunteers had been seated for 5 minutes (during which time informed consent, basic demographic information, and a focused medical history were obtained). First, peripheral oxygen saturation $\left(\mathrm{SpO}_{2}\right)$ and heart rate (HR) were measured with a finger pulse oximeter (Onyx 9500, Nonin Medical Inc., Plymouth, MN). Two investigators (MPL, JDV) recorded values when they remained constant for 30 seconds. Volunteers were blinded to the values so that they could not artificially increase their oxygenation by hyperventilating. Next, blood pressure (BP) was measured with a validated portable digital oscillometric blood pressure monitor (LifeSource UA-767, A\&D Medical, San Jose, CA). ${ }^{22}$ Respiratory rate (RR) was measured manually for 30 seconds while blood pressure was being taken. All measurements were taken on the right index finger $\left(\mathrm{SpO}_{2}, \mathrm{HR}\right)$ or right arm (BP) while volunteers were seated. Measurements were recorded inside a research tent warmer than the ambient temperature to ensure that perfusion to the fingers was adequate. The 6-minute walk test (6MWT) was conducted according to a standardized protocol. ${ }^{15}$ A 40 m outdoor course with an elevation change of $2 \mathrm{~m}$ was demarcated with cairns every $10 \mathrm{~m}$. Volunteers were instructed to walk as far as they could without jogging or running in 6 minutes. Two investigators (MPL, JDV) directly observed the volunteers during their 6MWT and recorded their 6MWD to the nearest $5 \mathrm{~m}$. Volunteers completed the 6MWT in the clothing and shoes or boots they were wearing at base camp without restrictions; on Aconcagua the weather is such that it is not customary to wear plastic mountaineering boots while acclimatizing at base camp. Upon termination of the 6MWT, volunteers returned to the research tent and were seated, where postexercise HR, $\mathrm{SpO}_{2}$, BP, and RR were recorded within the first minute in the same manner as described above. Delta vital signs were calculated and defined as resting vital signs minus post-exercise vital signs.

\section{DATA ANALYSIS}

We attempted to enroll every available volunteer. Realizing that many climbers would not summit and that survey response rates at high altitude are often low, a sample size calculation was performed prior to study enrollment. To identify a $4 \%$ decrease in $\mathrm{SpO}_{2}$ from a presumed baseline of $81.5 \%$ at $4200 \mathrm{~m},{ }^{14}$ we calculated that we would need 26 volunteers in each arm (reaching or not reaching the summit and presence or absence of AMS), assuming a 2-tailed analysis, an $\alpha$ of 0.05 , and a $\beta$ (power) of 0.9 .

Volunteers were defined as follows: "responders" completed the VS measurements, 6MWT, and returned their questionnaire with outcome data; "nonresponders" completed the VS measurements and 6MWT but did not return their questionnaire (thus outcome data are unavailable); "successful summit" were responders who reached a maximum altitude of $6962 \mathrm{~m}$; "unsuccessful summit" were responders who reached a maximum altitude of $<$ $6962 \mathrm{~m}$. AMS was defined as headache and LLSelf $\geq 3$. As with prior studies on Aconcagua, severe AMS was defined as headache and LLSelf $\geq 5 .{ }^{9}$ For data in which normality could be assured, means with $95 \%$ confidence intervals (CIs) are presented; where normality could not be assured, medians and interquartile ranges (IQRs) are presented. Comparisons of means were performed using Student's $t$ test, while comparisons of medians were performed using the Mann-Whitney U test. To identify predictors of successfully reaching the summit, logistic regression was performed to calculate odds ratios (OR) for the following variables: age, gender, body mass index, altitude of residence, previous maximum altitude reached, resting $\mathrm{SpO}_{2}, 6 \mathrm{MWD}$, postexercise $\mathrm{SpO}_{2}$, delta $\mathrm{SpO}_{2}$, ascent rate, and LLSelf. After identification of significant factors, the predictive nature of postexercise $\mathrm{SpO}_{2}$ was calculated using receiver operator characteristic (ROC) curve analysis, which yielded area under the curve (AUC) and standard descriptive test characteristics for the various cut points. All analyses were performed using Stata ${ }^{\circledR} 9.2$ for Macintosh (Stata Corporation, College Station, TX).

\section{Results}

During the 9-day study period, 543 mountaineers entered the park with permits declaring their intention to summit (data courtesy of Aconcagua Provincial Park authorities). One hundred twenty-four volunteers from 22 countries completed the 6MWT, and $64(51.6 \%)$ of these returned questionnaires with outcome data. Therefore, we enrolled $22.8 \%$ of all climbers attempting to summit Aconcagua during the study period. Mean time between each of the sites for the responders was as follows: 2.8 days (95\% CI: 2.2-3.4) from the Mendoza permit office to Horcones park entrance; 0.9 days (95\% CI: 0.7-1.1) from Horcones park entrance to Confluencia camp; 1.9 
Table 1. Volunteer characteristics

\begin{tabular}{|c|c|c|c|}
\hline & Successful summit $(n=36)$ & Unsuccessful summit $(n=28)$ & $p$ \\
\hline Gender ( $\%$ male $)$ & $94.4 \%$ & $85.7 \%$ & 0.235 \\
\hline Age $(\mathrm{yr})^{a}$ & $36.7(33.3-40.2)$ & $48.7(44.2-53.2)$ & $<0.0005$ \\
\hline Weight $(\mathrm{kg})$ & $76.5(73.1-79.1)$ & $77.1(72.2-82.0)$ & 0.831 \\
\hline Height (m) & $178.4(174.9-182.0)$ & $175.5(171.3-179.7)$ & 0.286 \\
\hline BMI & $24.2(22.8-25.5)$ & $24.9(23.9-26.0)$ & 0.392 \\
\hline \multicolumn{4}{|l|}{ Language } \\
\hline English & $69.4 \%$ & $71.4 \%$ & 0.181 \\
\hline French & $0 \%$ & $3.6 \%$ & \\
\hline German & $0 \%$ & $7.1 \%$ & \\
\hline Spanish & $30.6 \%$ & $17.9 \%$ & \\
\hline \multicolumn{4}{|l|}{ General past medical history (\%) } \\
\hline Anemia & $2.8 \%$ & $3.6 \%$ & 0.856 \\
\hline Asthma & $13.9 \%$ & $3.6 \%$ & 0.160 \\
\hline COPD & $5.6 \%$ & $7.1 \%$ & 0.795 \\
\hline Hypertension & $8.3 \%$ & $7.1 \%$ & 0.860 \\
\hline Myocardial infarction & $0 \%$ & $3.6 \%$ & 0.253 \\
\hline Valvular heart disease & $0 \%$ & $3.6 \%$ & 0.253 \\
\hline \multicolumn{4}{|l|}{ Previous altitude illness $(\%)$} \\
\hline Acute mountain sickness & $36.1 \%$ & $32.1 \%$ & 0.740 \\
\hline High altitude pulmonary edema & $2.8 \%$ & $0 \%$ & 0.374 \\
\hline High altitude cerebral edema & $0 \%$ & $0 \%$ & N/A \\
\hline \multicolumn{4}{|l|}{ Medications $(\%)^{b}$} \\
\hline Acetazolamide & $5.6 \%$ & $7.1 \%$ & 0.795 \\
\hline Ginkgo biloba & $11.1 \%$ & $0 \%$ & 0.069 \\
\hline Tobacco use $(\%)$ & $2.8 \%$ & $3.6 \%$ & 0.856 \\
\hline Alcohol use (\%) & $80.6 \%$ & $71.4 \%$ & 0.393 \\
\hline \multicolumn{4}{|l|}{ Altitude experience (m) } \\
\hline Altitude of residence & $692(388-967)$ & $500(192-808)$ & 0.375 \\
\hline Maximum previous altitude reached & $5695(5379-6012)$ & $5309(4856-5762)$ & 0.147 \\
\hline Maximum previous sleeping altitude & $4828(4490-5167)$ & $4459(3994-4924)$ & 0.184 \\
\hline
\end{tabular}

Means (95\% CIs) are reported.

${ }^{a}$ Statistically significant.

${ }^{b}$ No volunteers in either group were using prednisone, dexamethasone, nifedipine, or supplemental oxygen.

days (95\% CI: 1.8-2.1) from Confluencia camp to Plaza de Mulas base camp; and 7.6 days (95\% CI: 7.1-8.2) from Plaza de Mulas base camp to maximum altitude reached.

The baseline demographic and medical characteristics of the responders are shown in Table 1. Responders reached a mean maximum altitude of $6479 \mathrm{~m}$ (95\% CI: 6317-6641). Thirty-six (56\%) volunteers successfully reached the summit. The median LLSelf was 4 (IQR: 3.0-6.5); 76.6\% developed AMS, and 46.9\% developed severe AMS. The volunteers who successfully reached the summit were 11.9 years (95\% CI: 6.5-17.4) younger than the volunteers who did not. There were no other differences in baseline characteristics among the volunteers. Among responders and nonresponders, the only differences in baseline characteristics were that nonre- sponders were younger, more frequently non-English speakers, and more frequently used tobacco.

Among responders, the mean 6MWD was $469.5 \mathrm{~m}$ (95\% CI: 449.5-489.5; range: 320-750). During the study, none of the 6MWTs had to be terminated early due to exercise intolerance. Knowing that time spent acclimatizing at $4365 \mathrm{~m}$ prior to completion of the 6MWT may affect performance, we targeted enrollment in the study to coincide with climbers checking in with base camp physicians and park rangers, which typically occurred 12 to 24 hours after arrival at base camp. Over two-thirds of the 6MWTs were performed within 24 hours after arrival at $4365 \mathrm{~m}$. There was no correlation between 6MWD and hours after arrival at base camp.

Means, 95\% CIs, and group mean comparisons for resting, postexercise, and delta vital sign measurements 
Table 2. Objective measurements among climbers who successfully reached the summit and those who did not

\begin{tabular}{|c|c|c|c|c|}
\hline & Successful summit & Unsuccessful summit & Difference of means & $p$ \\
\hline \multicolumn{5}{|l|}{ Resting vital signs } \\
\hline HR (bpm) & $81.3(78.3$ to 84.3$)$ & 81.1 (74.8 to 87.4$)$ & $-0.2(-6.6$ to 6.2$)$ & 0.95 \\
\hline $\mathrm{SBP}(\mathrm{mmHg})$ & 144.1 (139.4 to 148.7$)$ & $146.6(140.1$ to 143.1$)$ & $2.6(-5.1$ to 10.2$)$ & 0.51 \\
\hline DBP (mmHg) & $87.3(84.5$ to 90.1$)$ & 90.7 (86.9 to 94.5$)$ & $3.4(-1.1$ to 7.9$)$ & 0.14 \\
\hline $\mathrm{RR}(\mathrm{bpm})$ & $17.8(16.7$ to 19.0$)$ & $17.8(16.8$ to 18.9$)$ & $0.0(-1.6$ to 1.6$)$ & 0.98 \\
\hline $\mathrm{SpO}_{2}(\%)^{a}$ & $86.3(85.1$ to 87.4$)$ & $83.9(81.9$ to 85.8$)$ & $-2.4(-4.5$ to -0.3$)$ & 0.02 \\
\hline \multicolumn{5}{|l|}{$6 \mathrm{MWT}$} \\
\hline 6MWD (m) & $482.9(451.8$ to 513.9$)$ & 452.4 (426.6 to 478.2$)$ & $-30.4(-71.6$ to 10.7$)$ & 0.14 \\
\hline Maximum HR (bpm) & $113.6(109.9$ to 117.3$)$ & $113.4(106.7$ to 120.0$)$ & $-0.2(-7.2$ to 6.8$)$ & 0.95 \\
\hline \multicolumn{5}{|l|}{ Postexercise vital signs } \\
\hline HR (bpm) & 98.2 (93.0 to 103.5$)$ & 102.7 (95.7 to 109.7$)$ & $4.5(-3.9$ to 12.9$)$ & 0.29 \\
\hline SBP $(\mathrm{mmHg})$ & $143.9(138.6$ to 149.1$)$ & $149.6(141.9$ to 157.4$)$ & $5.6(-3.1$ to 14.7$)$ & 0.20 \\
\hline DBP (mmHg) & $86.8(84.1$ to 89.4$)$ & $87.6(84.2$ to 91.0$)$ & $0.8(-3.3$ to 5.0$)$ & 0.69 \\
\hline $\mathrm{RR}$ (bpm) & $19.6(18.3$ to 20.8$)$ & $20.8(19.4$ to 22.1$)$ & $1.2(-0.6$ to 3.1$)$ & 0.19 \\
\hline $\mathrm{SpO}_{2}(\%)^{a}$ & $80.8(79.4$ to 82.1$)$ & $76.4(74.3$ to 78.5$)$ & $-4.4(-6.7$ to -2.0$)$ & $<0.0005$ \\
\hline \multicolumn{5}{|l|}{ Delta vital signs } \\
\hline $\mathrm{HR}$ (bpm) & $17.0(15.5$ to 21.4$)$ & $21.6(15.9$ to 27.3$)$ & $4.7(-2.3$ to 11.7$)$ & 0.19 \\
\hline $\mathrm{SBP}(\mathrm{mmHg})$ & $-0.2(-4.6$ to 4.2$)$ & $3.0(-1.2$ to 7.3$)$ & $3.2(-2.9$ to 9.4$)$ & 0.30 \\
\hline DBP $(\mathrm{mmHg})$ & $-0.6(-3.2$ to 2.1$)$ & $-3.1(-6.2$ to -0.1$)$ & $-2.6(-6.5$ to 1.3$)$ & 0.19 \\
\hline $\mathrm{RR}(\mathrm{bpm})$ & $1.7(0.8$ to 2.6$)$ & $2.9(1.6$ to 4.3$)$ & $1.2(-0.3$ to 2.7$)$ & 0.12 \\
\hline $\mathrm{SpO}_{2}(\%)$ & $-5.5(-7.2$ to -3.9$)$ & $-7.5(-9.1$ to -5.9$)$ & $-1.9(-4.2$ to 0.4$)$ & 0.10 \\
\hline Maximum altitude reached $(\mathrm{m})^{a}$ & 6962 & $5891(5684$ to 6098$)$ & $-1071(-1248$ to -894$)$ & $<0.0005$ \\
\hline Ascent rate $(\mathrm{m} / \mathrm{d})$ & 403.5 (375.5 to 431.6$)$ & 376.7 (314.1 to 439.2$)$ & $-26.9(-88.2$ to 34.4$)$ & 0.38 \\
\hline LLS & $4(3$ to 7.5$)$ & $5(3.5$ to 6.5$)$ & N/A & 0.63 \\
\hline
\end{tabular}

Means (95\% CIs) are reported for all measurements except LLS, where medians (IQRs) are reported.

${ }^{a}$ Statistically significant.

$\mathrm{HR}$, heart rate; SBP, systolic blood pressure; $\mathrm{DBP}$, diastolic blood pressure; RR, respiratory rate; $\mathrm{SpO}_{2}$, peripheral oxygen saturation; 6MWT, 6-minute walk test; 6MWD, 6-minute walk distance; LLS, Lake Louise Self-Report Score.

among summiters and nonsummiters are shown in Table 2. There was a statistically significant difference in both resting and postexercise $\mathrm{SpO}_{2}$ among the summiters and nonsummiters. There was no association between HR, systolic BP (SBP), diastolic BP (DBP), RR, 6MWD, ascent rate, or LLSelf and the outcome of successfully reaching the summit. There was no association between any of the resting or postexercise vital sign measurements, 6MWD, or ascent rate for the outcome of AMS (data not shown). Furthermore, there was no difference in resting, postexercise, or delta vital sign measurements nor 6MWD among the responders and nonresponders.

Age (OR:0.91, 95\% CI: 0.85-0.96) and postexercise $\mathrm{SpO}_{2}$ (OR:1.25, 95\% CI: 1.06-1.48) were identified in the logistic regression model as significant predictors of summit success. Resting $\mathrm{SpO}_{2}$ was not a statistically significant predictor of summit success (OR: 1.15, 95\% CI: 0.97-1.37). We then performed a post hoc analysis of the screening ability of postexercise $\mathrm{SpO}_{2}$ to predict successfully reaching the summit by investigation of the ROC curve. The optimum cut point to maximize the sensitivity of postexercise $\mathrm{SpO}_{2}$ as a screening tool for predicting who would successfully reach the summit was determined to be post-exercise $\mathrm{SpO}_{2} \geq 75 \%$. As shown in Figure 2, utilizing a postexercise $\mathrm{SpO}_{2}$ cut point of $\geq$ $75 \%$ resulted in AUC of 0.749 (95\% CI: 0.626-0.850). This yielded a sensitivity of $97.2 \%$, specificity of $32.1 \%$, positive predictive value (PPV) of $64.8 \%$, negative predictive value (NPV) of $90 \%$, positive likelihood ratio $(\mathrm{LR}+)$ of 1.43 , and negative likelihood ratio $(\mathrm{LR}-)$ of 0.086 . Only one subject with a postexercise $\mathrm{SpO}_{2}<75 \%$ successfully reached the summit (Table 3 ).

Finally, to investigate the potential confounder of summit weather on successful summit attempts, we abstracted weather data for the days on which the study was performed. There was no statistically significant association between wind chill, wind speed, or visibility and successfully reaching the summit (data not shown).

\section{Discussion}

We have shown that the 6MWT is feasible to perform at high altitude in a harsh outdoor mountain environment. We present baseline vital signs measurements, 6MWD, 


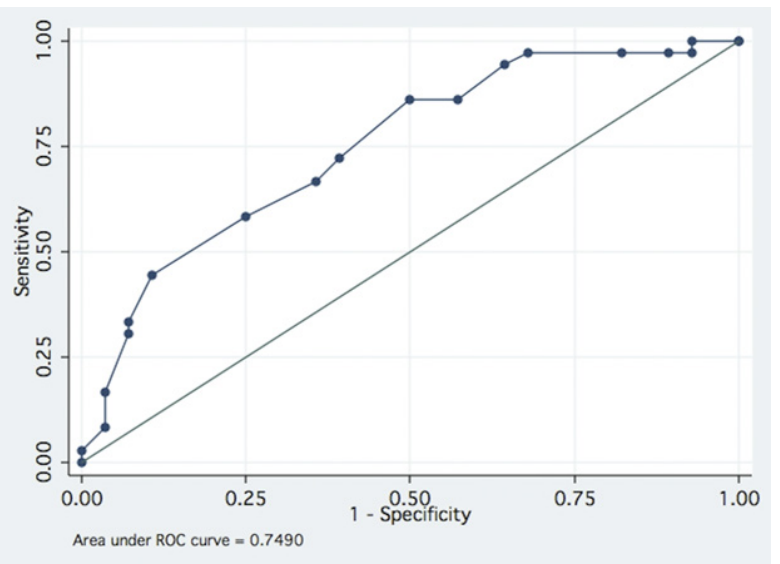

Figure 2. Graph of the receiver operator characteristic curve demonstrating the predictive value of postexercise $\mathrm{SpO}_{2}$ for predicting the outcome of successfully reaching the summit of Aconcagua. Of the 36 climbers who successfully reached the summit of Aconcagua, only one climber had a postexercise $\mathrm{SpO}_{2}<75 \%$.

and postexercise vital signs measurements in healthy adult mountaineers at $4365 \mathrm{~m}$. Age and postexercise $\mathrm{SpO}_{2}$ were significantly associated with summit success. In our sample a postexercise $\mathrm{SpO}_{2}<75 \%$ had $97.2 \%$ sensitivity and a negative likelihood ratio of 0.086 in predicting the outcome of successfully reaching the summit. Despite the harsh environment at this altitude and the high degree of resting hypoxia, volunteers were willing and eager to participate, no adverse events were reported, and the study was done with minimal cost or equipment.

The 6MWT is a functional exercise test that has been extensively studied in the cardiovascular literature and has been shown to be both reliable and valid across multiple cardiopulmonary diseases. A limited number of studies have begun to investigate dynamic vital sign measurement as surrogates for overall functional status at high altitude. Tannheimer and colleagues have conducted two such studies. In one study, German soldiers ran up a flight of stairs over a distance of $90 \mathrm{~m}$ and a change in altitude of $46 \mathrm{~m}$ at a high altitude hut at $3371 \mathrm{~m}$. In this group, postexercise peripheral oxygen saturation was a more sensitive predictor of an individ- ual's degree of acclimatization than resting peripheral oxygen saturation. ${ }^{23}$ In a second study, climbers walked at their maximum speed on a $100 \mathrm{~m}$ course with an altitude difference of $30 \mathrm{~m}$, and time and maximum heart rate were recorded. There was a correlation between postexercise peripheral oxygen saturation at $4850 \mathrm{~m}$ and maximum altitude reached at extreme altitude on an 8047 m peak. ${ }^{24}$ We chose to utilize the 6MWT as the provocative test in our study because it requires no infrastructure and has been externally validated for multiple cardiopulmonary diseases.

Our findings suggest that measurement of 6MWD and subsequent postexercise $\mathrm{SpO}_{2}$ may be useful screening tests on extreme altitude expeditions. It is difficult to screen mountaineers for the subsequent development of outcomes such as AMS or not successfully reaching a summit due to the multifactorial nature of these outcomes. Predicting performance at extreme altitude has traditionally involved identifying characteristics that predict who will subsequently develop AMS, utilizing historical components and single static vital sign measurements. The goal of screening mountaineers at high altitude base camps is to predict who will have an adverse event as they continue towards the extreme altitude summit. One prior study on Aconcagua has reported that successfully reaching the summit is independent of the development of AMS. ${ }^{9}$ This is likely due to the high incidence of AMS on Aconcagua as well as the fortitude of mountaineers in continuing towards the summit despite developing some degree of AMS. Thus, a better outcome to screen for at base camp may actually be not successfully reaching the summit, as opposed to development of AMS. Because dynamic objective measurements of functional status such as the $6 \mathrm{MWT}$ and postexercise $\mathrm{SpO}_{2}$ simulate the work performed by mountaineers at extreme altitude on an expedition, they may be more optimal screening tests than static vital signs measurements or questionnaires. In our study, the overall rate (or pretest probability) of successfully reaching the summit was $56 \%$, and the rate of not successfully reaching the summit was $44 \%$. If the postexercise $\mathrm{SpO}_{2}$ is thought of as a screening test to modify the probability of reaching the summit, applying

Table 3. Two-by-two table demonstrating the screening ability of postexercise peripheral oxygen saturation $\left(\mathrm{SpO}_{2}\right)$

$$
\text { Successful summit Unsuccessful summit }
$$

$\begin{array}{cccc}\text { Postexercise } \mathrm{SpO}_{2} \geq 75 \% & 35 & 19 & 54 \text { PPV: 64.8\% (50.6-77.3\%) } \\ \text { Postexercise } \mathrm{SpO}_{2}<75 \% & 1 & 9 & 10 \text { NPV: } 90.0 \%(55.5-99.7 \%) \\ & 36 & 28 & 64\end{array}$

PPV, positive predictive value; NPV, negative predictive value. Positive likelihood ratio (LR+): 1.43. Negative likelihood ratio (LR-): 0.086. 


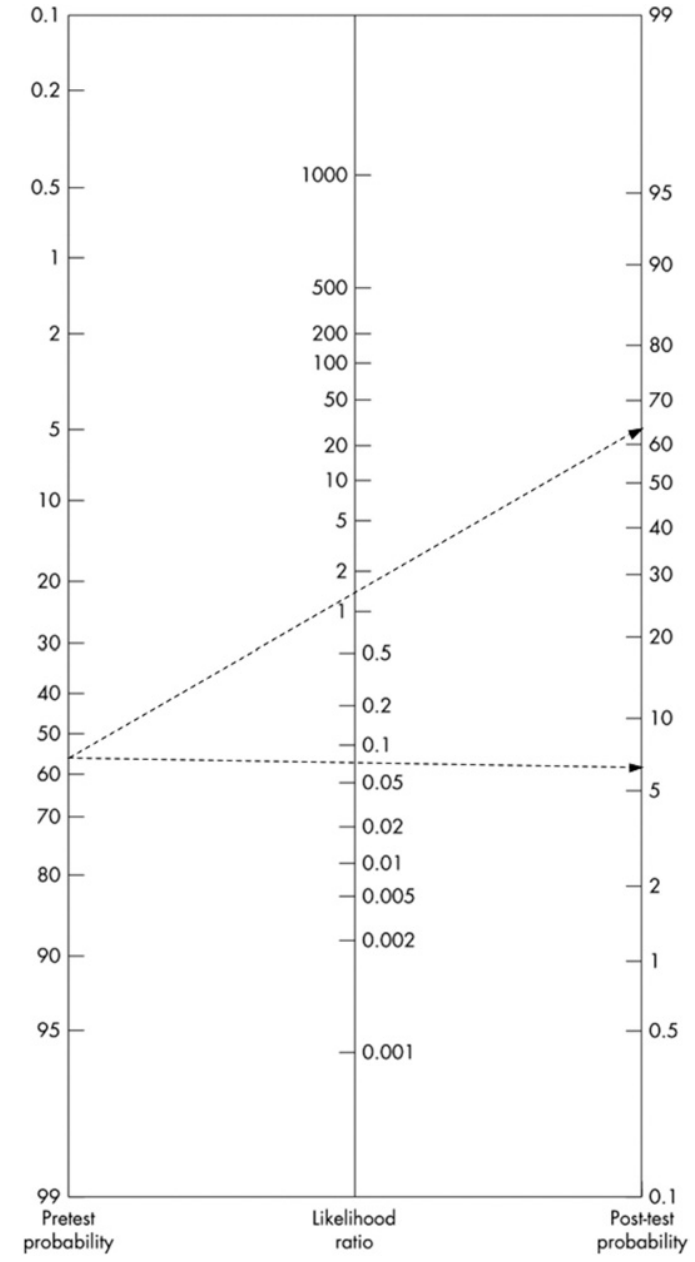

Figure 3. Fagan nomogram demonstrating posttest probability for successfully reaching the summit of Aconcagua based on postexercise $\mathrm{SpO}_{2}$ as a screening test. The pretest probability of successfully reaching the summit of Aconcagua (6962 m) was 56\%. For climbers who complete a 6MWT and have a postexercise $\mathrm{SpO}_{2}<75 \%$, the LR - of 0.086 results in a posttest probability of successfully reaching the summit of $6 \%$. This nomogram is modified from Fagan. ${ }^{25}$

the LR - of 0.086 to the Fagan nomogram results in a posttest probability of successfully reaching the summit for climbers with postexercise $\mathrm{SpO}_{2}<75 \%$ of $6 \%$ (Figure 3). ${ }^{25}$ For climbers with postexercise $\mathrm{SpO}_{2} \geq$ $75 \%$, the posttest probability remains relatively unchanged at $62 \%$. As with any diagnostic test based on a continuous variable, finding the optimal cut point on an ROC curve is a balance between optimizing the sensitivity or specificity. Thus, the actual predictive value and optimum cut point of a screening test such as postexercise $\mathrm{SpO}_{2}$ may vary from one setting or sample to another. Regardless, the ease of use and potential significance is suggested here.

Presently, base camp physicians on Aconcagua utilize static vital sign measurements, namely, resting blood pressure and resting $\mathrm{SpO}_{2}$, to screen for $\mathrm{HAI}$ as climbers ascend. ${ }^{13,26}$ In our study, there was no correlation between static vital sign measurements and development of AMS. However, there was a correlation between resting $\mathrm{SpO}_{2}$ and successfully reaching the summit. Exercise exaggerated this correlation, and the difference in postexercise $\mathrm{SpO}_{2}$ among the volunteers that did and did not summit was even greater than the difference in resting $\mathrm{SpO}_{2}$. In the 2008-2009 climbing season on Aconcagua, there were at least 6 deaths and almost daily helicopter evacuations. As such, effective screening tests are essential to base camp medical personnel, who are faced with recommending for which climbers it is not safe to continue on their expeditions. For example, if a climber who was acclimatizing at base camp checked in with the base camp physicians, completed a 6MWT, and had a postexercise $\mathrm{SpO}_{2}$ of $72 \%$, he could be counseled that his likelihood of reaching the summit is quite low. Predictive data could independently inform climbers, partners, and guides, thereby objectively influencing important midtrek decisions. It is important to recognize that application of postexercise $\mathrm{SpO}_{2}$ as a screening test would not predict who would successfully reach the summit. Rather, it would identify the subset of climbers whose postexercise $\mathrm{SpO}_{2}$ was below a threshold (in this study, $75 \%$ ) such that their likelihood of successfully reaching the summit is very low (in this study, 6\%). Importantly, ours was a pilot study of 64 climbers, and prior to the application of this or other screening tests on a broad scale, studies with larger sample sizes are needed. However, if validated, the use of postexercise $\mathrm{SpO}_{2}$ may represent a significant addition to the present screening process on Aconcagua and other mountains at high or extreme altitude.

There are some limitations to our work that should be considered. First, the 6MWT conducted in this study was inherently different than other studies of the 6MWT due to the environment in which it was performed. American Thoracic Society guidelines recommend performing the 6MWT in a straight, level, climate-controlled indoor corridor 25 to $50 \mathrm{~m}$ in length with markers every $3 \mathrm{~m}^{15}$ These luxuries were not available in the extreme environment at base camp at an altitude of $4365 \mathrm{~m}$. Our course was shared with other climbers, park rangers, and pack mules, which may have distracted the volunteers. It was $40 \mathrm{~m}$ in length, had stone cairns every $10 \mathrm{~m}$, was not entirely straight, and had a $2 \mathrm{~m}$ elevation change from the start to the end of the course. Because our volunteers completed laps on the course, we believe the slope had minimal effect on 6MWD. Secondly, weather may have affected 6MWD and vital sign measurements. During data collection at Plaza de Mulas base camp, the ambient temperature ranged from -7 to $3^{\circ} \mathrm{C}$, wind ranged from 5 
to $30 \mathrm{~km} / \mathrm{h}$, and wind chill ranged from -13 to $-3^{\circ} \mathrm{C}$. All but 2 days of data collection were sunny and clear; on those 2 days, however, 17 and $3 \mathrm{~cm}$ of snow fell. As such, weather may have limited performance on 6MWT as well as artificially decreased postexercise $\mathrm{SpO}_{2}$ (measured on a finger pulse oximeter) via cold-induced peripheral vasoconstriction. Third, the volunteers who successfully reached the summit were younger than those who did not. This age difference partially explains the difference in postexercise $\mathrm{SpO}_{2}$ we found. Finally, our response rate was $52.4 \%$, resulting in 64 volunteers with complete data available for analysis. It is commonly reported that studies of HAI often involve limited numbers of volunteers due to the complex environmental nature in which they take place. ${ }^{27}$ Volatile weather, hypobaric hypoxic conditions at $4365 \mathrm{~m}$ (barometric pressure $61 \mathrm{kPa}$ [454 $\mathrm{mmHg}$ ]; ambient partial pressure of oxygen $12.7 \mathrm{kPa}$ [95 $\mathrm{mmHg}]$ ) and above, multiple spoken languages, and daily helicopter evacuations all may have reduced our overall response rate. However, our response rate is consistent with past surveys of HAI in the field at high altitude, which reported response rates of $34 \%,{ }^{10} 55.4 \%,{ }^{28}$ and $56.6 \% .^{29}$ The lack of statistically significant differences in any of the 16 objective measurements between respondents and nonrespondents suggests that nonresponders were similar to responders at baseline.

There are a number of research implications to come from these pilot data. We performed the 6MWT in civilians on a single mountain. Additional studies are needed to externally validate the feasibility of performing the 6MWT on other mountains at high altitude. It will be important to determine which validated and realiable submaximal cardiopulmonary test, be it the 6MWT, a step test, or another provocative test, is the most reproducible and easiest to use at high altitude. Additionally, studies are needed on Aconcagua that identify those climbers who are evacuated via helicopter. Finally, studies with larger sample sizes and higher response rates are needed to investigate the screening ability of postexercise $\mathrm{SpO}_{2}$ for the development of AMS or successfully reaching a summit at extreme altitude. An ideal mountain for this investigation would be Kilimanjaro, which like Aconcagua is one of the seven summits and annually attracts climbers of varying physical condition. If postexercise $\mathrm{SpO}_{2}$ is validated as a sensitive predictor of who is unlikely to summit, further studies could characterize the optimum cutoff value for various mountains that see large numbers of helicopter evacuations. The concept of a dynamic measurement of functional status at high altitude is an important one that will surely be explored more in the future, as high altitude mountain- eering increases in popularity and global conflicts continue in high altitude settings.

\section{Conclusion}

In summary, the 6MWT is an inexpensive, noninvasive test of functional exercise capacity that is feasible to perform at high altitude and resulted in exercise-induced worsening of hypoxia. In this study, 124 adult mountaineers walked a mean of $458 \mathrm{~m}$ at high altitude. Measurement of postexercise $\mathrm{SpO}_{2}$ after completion of the 6MWT was a useful screening test for predicting who would successfully reach the summit. Among 64 climbers who returned surveys detailing their maximum altitude reached, the likelihood of successfully reaching the summit was $65 \%$ for those with postexercise $\mathrm{SpO}_{2} \geq$ $75 \%$, while this number was only $10 \%$ for climbers with a postexercise $\mathrm{SpO}_{2}<75 \%$. Future work is needed to further define the role of the 6MWT and postexercise vital sign measurements as screening tests at high altitude.

\section{Disclosure}

None of the authors have any institutional or commercial affiliations that might pose a conflict of interest regarding the publication of this manuscript to disclose.

\section{Ethical Approval}

The Institutional Review Board of Northwestern University (IRB \#2863-001) and the Mendoza Provincial Department of Natural Resources (Resolución \#836) granted approval of human subjects research. All volunteers signed a document of informed consent.

\section{Acknowledgments}

The authors wish to thank Heber Orona, Roel Quique Apolinario Villafán, and the staff of Aconcagua Trek for their expedition support; the base camp physicians and park rangers of Aconcagua Provincial Park for their time, equipment, and cooperation; Marisa Chumil and Silvia Palmerin for their Spanish translations; François Blumenfeld and Eliana Vagalau for their French translations; Kristina Ogilvie and Misha Kovacevic for their German translations; and James Harris of Orbital Technologies Corporation for constructing the drop-boxes.

\section{References}

1. Hackett P, Roach R. High-altitude medicine. In: Auerbach $\mathrm{P}$, ed. Wilderness Medicine. 5th ed. Philadelphia: Mosby Elsevier; 2007:1-2. 
2. Milledge JS, Beeley JM, Broome J, et al. Acute mountain sickness susceptibility, fitness and hypoxic ventilatory response. Eur Respir J. 1991;4:1000-1003.

3. Hackett PH, Roach RC. High-altitude illness. N Engl J Med. 2001;345:107-114.

4. Schneider M, Bernasch D, Weymann J, Holle R, Bartsch P. Acute mountain sickness: influence of susceptibility, preexposure, and ascent rate. Med Sci Sports Exerc. 2002;34: 1886-1891.

5. Ziaee V, Yunesian M, Ahmadinejad Z, et al. Acute mountain sickness in Iranian trekkers around Mount Damavand (5671 m) in Iran. Wilderness Environ Med. 2003;14: 214-219.

6. Burtscher M, Flatz M, Faulhaber M. Prediction of susceptibility to acute mountain sickness by $\mathrm{SaO}_{2}$ values during short-term exposure to hypoxia. High Alt Med Biol. 2004; 5:335-340.

7. O'Connor T, Dubowitz G, Bickler PE. Pulse oximetry in the diagnosis of acute mountain sickness. High Alt Med Biol. 2004;5:341-348.

8. Basnyat B, Lemaster J, Litch JA. Everest or bust: a cross sectional, epidemiological study of acute mountain sickness at 4243 meters in the Himalayas. Aviat Space Environ Med. 1999;70:867-873.

9. Pesce C, Leal C, Pinto H, et al. Determinants of acute mountain sickness and success on Mount Aconcagua (6962 m). High Alt Med Biol. 2005;6:158-166.

10. Wiseman C, Freer L, Hung E. Physical and medical characteristics of successful and unsuccessful summiteers of Mount Everest in 2003. Wilderness Environ Med. 2006; 17:103-108.

11. Davies AJ, Kalson NS, Stokes S, et al. Determinants of summiting success and acute mountain sickness on Mt Kilimanjaro (5895 m). Wilderness Environ Med. 2009;20: 311-317.

12. Freer L. Descriptive report of experience designing and staffing the first-ever medical clinic at Mt. Everest base camp, 2003. High Alt Med Biol. 2004;5:89-90.

13. Windsor JS, Currie RJ, Grocott M, Chioconi R, Hillebrandt D. Health screening on Aconcagua. Wilderness Environ Med. 2009;20:90-104.

14. Roach RC, Greene ER, Schoene RB, Hackett PH. Arterial oxygen saturation for prediction of acute mountain sickness. Aviat Space Environ Med. 1998;69:1182-1185.

15. ATS statement: guidelines for the six-minute walk test. Am J Respir Crit Care Med. 2002;166:111-117.
16. Lipkin DP, Scriven AJ, Crake T, Poole-Wilson PA. Six minute walking test for assessing exercise capacity in chronic heart failure. $\mathrm{Br}$ Med J (Clin Res Ed). 1986; 292:653-635.

17. Butland RJ, Pang J, Gross ER, Woodcock AA, Geddes DM. Two-, six-, and 12-minute walking tests in respiratory disease. Br Med J (Clin Res Ed). 1982;284:1607-1608.

18. Ciurzynski M, Kurzyna M, Bochowicz A, et al. Long-term effects of acute pulmonary embolism on echocardiographic Doppler indices and functional capacity. Clin Cardiol. 2004;27:693-697.

19. Montgomery PS, Gardner AW. The clinical utility of a six-minute walk test in peripheral arterial occlusive disease patients. J Am Geriatr Soc. 1998;46:706-711.

20. Gulmans VA, van Veldhoven NH, de Meer K, Helders PJ. The six-minute walking test in children with cystic fibrosis: reliability and validity. Pediatr Pulmonol. 1996;22:85-89.

21. Roach R, Bartsch P, Hackett P, Oelz O. The Lake Louise acute mountain sickness scoring system. In: Sutton JR, Houston CS, Coates G, eds. Hypoxia and Molecular Medicine. Burlington, VT: Queen City Printers; 1993:272-274.

22. Rogoza AN, Pavlova TS, Sergeeva MV. Validation of A\&D UA-767 device for the self-measurement of blood pressure. Blood Press Monit. 2000;5:227-231.

23. Tannheimer M, Albertini N, Ulmer HV, et al. Testing individual risk of acute mountain sickness at greater altitudes. Mil Med. 2009;174:363-369.

24. Tannheimer M, Thomas A, Gerngross H. Oxygen saturation course and altitude symptomatology during an expedition to Broad Peak (8047 m). Int J Sports Med. 2002;23: $329-335$.

25. Fagan TJ. Nomogram for Bayes theorem. $N$ Engl J Med. 1975;293:257.

26. Lazio MP, Van Roo JD, Malik S, Courtney DM, Pesce C. In response to "Health screening on Aconcagua." Wilderness Environ Med. 2009;20:393-394.

27. Roach R, Kayser B. Measuring mountain maladies. High Alt Med Biol. 2007;8:171-172.

28. Dellasanta P, Gaillard S, Loutan L, Kayser B. Comparing questionnaires for the assessment of acute mountain sickness. High Alt Med Biol. 2007;8:184-191.

29. Onopa J, Haley A, Yeow ME. Survey of acute mountain sickness on Mauna Kea. High Alt Med Biol. 2007;8: 200-205. 